\title{
Work in and for a Healthy City
}

\author{
Juliana Martins ${ }^{1}$
}

Accepted: 15 February 2021 / Published online: 10 March 2021

(c) The Author(s), under exclusive licence to Springer Nature Limited part of Springer Nature 2021

The image of Zoom meetings with work colleagues captures the extraordinary experience of work during the Covid-19 pandemic: a massive, forced and sudden move to homeworking in several sectors of activity from banks to education. It is early to say how transformative this experience will be for post-pandemic urban life. But there is little doubt that work has been tremendously affected by the crisis bringing about short- and long-term impacts at individual and urban levels.

The sphere of work-both in what concerns our working life and more broadly our economy and productive activities-has not only been affected by this health crisis; it plays a major role in securing a healthier urban future. In this commentary, I argue that work should be a fundamental area of concern for urban design researchers and practitioners in the pursuit of a Healthy City, as we move through and out of the crisis. Current approaches to health city planning and design call for holistic perspectives that consider personal, social and economic health determinants influenced by the built environment. While work is not particularly well elaborated in existing literature on healthy cities, the way in which the built environment accommodates (inclusive and diverse) urban economies and (the variety of) work patterns matters for health.

I advance three dimensions of work that are relevant for (designing) a healthier built environment: Urban Economies, Place(s) of Work and Work/Economy in Place. Urban Design - through elements such as urban form and street networks, building types, mix of uses, or open spacesplays a key role in ensuring that urban space accommodates work and economic activities in healthy ways across these dimensions. However, work is surprisingly overlooked in Urban Design. How much do we know about the spatial requirements of different economic activities or the implications of remote work for urban space? This crisis offers an

Juliana Martins

j.martins@ucl.ac.uk

1 Bartlett School of Planning, University College London, 14 Upper Woburn Place, 5th floor, London WC1H 0NN, UK opportunity for the field to further engage with this forgotten dimension and set out a more ambitious research and practice agenda for building Healthy Cities.

\section{Work: a forgotten dimension in Urban Design research}

While seminal works on planning and design of cities considered the relationship (and often segregation) of living and working, particularly in industry, to develop healthier urban environments (Sarkar et al. 2014), the field of Urban Design has arguably paid little attention to working life and urban economies.

There are some notable contributions to the topic from both research and practice. In architecture, research has explored, for example, relationships between offices' layout and the organisation of work (Sailer and Penn 2009) and the future of the workplace (Duffy 2008). In planning, a burgeoning line of enquiry has examined urban manufacturing, highlighting the need to retain industrial land in cities and rethink the mix of industry and other activities, namely residential (Ferm and Jones 2017). The integration of work and production in the city has been further discussed in practice-based research (Beunderman et al. 2018) and professional organisations publications (Urban Design Group 2016; New London Architecture 2016). In Urban Design, Montgomery $(2005,2007)$ made a key contribution, looking at urban economies and placemaking. Some studies critically investigated the role of urban design in local economic regeneration but focussed mainly on how it is used to attract investment (Hubbard 1995). Emergent research on creative clusters has further explored urban design perspectives on the economy, highlighting the role of the built environment at different scales (Stevens 2015) and the extension of work to a variety of semi-public and public spaces (Martins 2015). More recently, Zenkteler et al. (2021) investigated the role of suburbs in the knowledge economy in the context of remote working practices. 
But these are exceptions within a largely overlooked issue. Although Gospodini (2002) has identified new uses of urban design driven by inter-city economic competition, this did not resonate much in advancing research agendas around the economy and the built environment. Issues such as the spatiality of work, implications of new ways of working (e.g. flexible working), and patterns and spatial requirements of economic activities have been mostly absent from the debate. Little attention has also been paid to the characteristics and design of working districts more generally. And while some relevant issues, such as the need to mix uses, are frequently mentioned in research and practice debates, the discussion is often generic with limited scrutiny of what such mixing entails in terms of urban form and building types, the spatial needs of different (productive/residential) uses, or conflicts around movement of goods and people, air quality, noise, or use of space. Urban design can and should do more.

The pandemic's impacts on working lives and the economy brought work to the centre of the debate on the future of cities. It stimulated an intense discussion about work and workplaces and claims about the death of the office re-emerged once again (Nixey 2020; Nathan 2020; Perry 2020). Arguably, the crisis' impact has been to reinforcebrutally - a trend towards flexible work that started decades ago (Harris 2015) yet never fulfilling these radical predictions. Although it is early to understand the extent and longterm impacts of this forced shift to remote working, some anecdotal evidence suggests that companies will boost flexible and homeworking (BBC News 2020). But rather than the death of the office, this will likely mean more diverse and fragmented workplaces, a combination of smaller and (re)localised offices with shared models, home offices, and extended workplaces across cafes, hotels, etc. Despite these uncertainties about the future, it is undeniable that there will be far-reaching transformations in how work and the economy shall be accommodated in urban space(s). The current health crisis reinforces the need for a more robust approach to work in urban design that can grasp its wider spatial implications and needs in its multiple relationships with social life, and physical and mental well-being.

\section{The role of Work in Healthy Cities}

Relationships between health and the built environment are complex and multifaceted (Sarkar and Webster 2017). While there are several frameworks to conceptualise these relationships, the current paradigm is holistic and multidisciplinary and "calls for a broader perspective-one that moves away from the traditional health concerns of urban planning and into a comprehensive realm which links the functions of urban planning and the creation of strong, healthy and vibrant neighbourhoods, towns and cities" (Duhl and Sanchez 1999, p. 17). In this context, the sphere of work is of great relevance.

But the role of work in healthy cities' frameworks is not always explicit (Bird et al. 2018). Barton's (2005) influential settlement ecosystem health map shows that work is implicated in a range of dimensions and scales namely local economy (e.g. its structure, employment opportunities), human activities and movement (e.g. working), and built environment (buildings, places and spaces where activities happen). A recent framework (THRIVES) stresses the need to reframe the concept of healthy urban development "to encompass the connected lenses of sustainability, equity and inclusion and the consideration of health impacts at multiple spatial and temporal dimensions" (Pineo 2020, p. 1). While this framework does not elaborate on work, these core principles reinforce its relevance, especially regarding the health consequences of environmental breakdown (e.g. commuting patterns) and uneven impacts of urban development across different groups (e.g. access to jobs).

The Covid-19 crisis further reinforces the need to understand and conceptualise the links between work and health regarding physical and mental well-being, social health determinants, and inclusion, equity, and sustainability (Shaw et al. 2020). The shift to remote working raised challenges around managing work commitments and simultaneously attend pressing family needs (e.g. childcare), and physical and mental health when working from (often tiny and crowded) residences (Reuschke and Felstead 2020). For many, lockdowns led to job loss or compulsory furlough, with serious impacts on present and future income. For key and service workers, who did not have the choice to home retreat, work simply became more dangerous (Avdiu and Nayyar 2020). The health crisis exposed and reinforced persisting work and health inequalities. Restrictions in movement additionally had a massive economic impact, putting many businesses at risk, including those that are important to city life such as street-based retail and hospitality and, more generally, across most economic sectors. Lockdowns not only led to empty offices, but also empty cities.

It is thus timely to further elaborate the role of work in planning and designing healthy cities. I propose to conceptualise these relationships across three dimensions: Urban Economies, Place(s) of Work, and Work/Economy in Place. Table 1 shows how these contribute (directly and indirectly) to spheres and principles of the frameworks discussed above. While there are other work/economic factors that affect health, the focus here is on issues that are related to the built environment and relevant for urban design.

These three dimensions are connected to health in multiple ways. 
Table 1 Relationships between Work, Healthy Cities' frameworks, and Urban Design

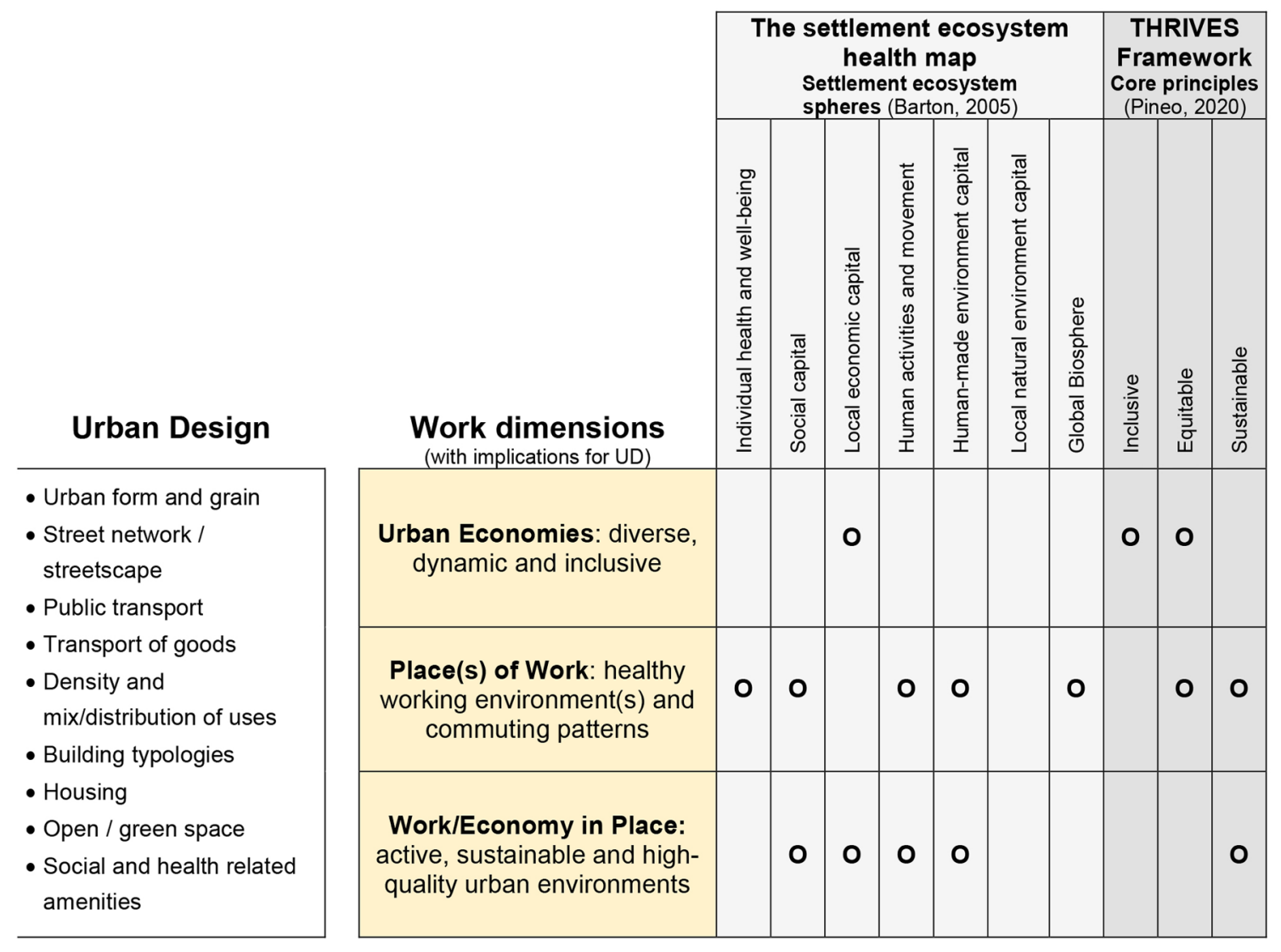

\section{Urban economies}

The diversity, strength and inclusivity of urban economies is paramount. Access to work is key for inclusion in society and income which is "probably the biggest determinant of health" (Barton 2005, p. 349). A more diverse economy, that builds upon several sectors (including manufacturing) can offer a broader range of job types and opportunities. As Barton (2005, p. 349) summarises the "structure and dynamic of the local economy, the degree to which it creates employment opportunities for different population sectors, are important for health". The pandemic crisis additionally exposed the risks of relying on few economic sectors (i.e. tourism), and the vulnerability of complex international logistical chains, reinforcing an agenda to incorporate industry in cities. The type of work is not only associated with income but also job (in)security and safety, determining exposure to occupational hazards and protection in a health crisis.

\section{Place(s) of work}

The location and distribution of work is important for health in several ways. First, at a wider scale, commuting for work represents a large portion of trips; how we move to and from work is thus crucial for promoting physical activity and walkability, improve air quality, and halt climate change and environmental breakdown. Second, the trend towards remote, flexible and homework has health implications related, for example, with the suitability of homes for healthy homeworking, balance between work and personal life, and access to social networks. More generally, the quality of working areas, where people spend much of their time, and the access these provide to open and green space, good air quality, and opportunities for physical activity and social contacts are crucial for mental and physical well-being.

\section{Work/economy in place}

Health is also associated with quality of place, in particular the vibrancy and sustainability of neighbourhoods/cities (Duhl and Sanchez 1999). Employment hubs draw in critical mass that supports retail, hospitality, and other urban and social activities that boost urban life. The presence of these activities is crucial for providing access to healthy consumption options (e.g. food, etc.) and essential services, and more generally for the creation of high-quality urban environments. Changes in the location and patterns of work have impacts on the distribution of this critical mass, and thus on the viability of some of these activities and liveliness of 
streets/public spaces. In parallel, technological and organisational developments are radically transforming some economic activities, namely retail, with massive implications for street-based activity.

\section{Researching and designing Work in and for a Healthy City}

Urban Design plays a key role in providing a built environment that suitably accommodates work and economic activities in healthy ways, and maximises the benefits for health, well-being, equity, and sustainability of changing ways of working. A number of challenges and implications for design, at several scales, are raised across the three dimensions, laying the ground for a research and design agenda on work and the economy in relation to Healthy Cities.

Regarding Urban Economies, it is paramount to accommodate a diversity and mix of productive/economic activities in the city, including not only dynamic and emergent sectors (such as tech and creative industries) but also manufacturing. This requires urban form and building typologies that are fit to accommodate these activities, articulate their different buildings' scales and needs regarding flows of goods and people, and manage their relationship with residential and other uses. Urban design research should further examine how different productive activities operate spatially.

There is also an opportunity to reflect on how the design of the built environment may foster the development of industries that contribute to health and sustainability (e.g. green economy), circular economies, and to hinder workrelated health inequalities.

Places of Work have implications for urban design at several scales. Accessibility to workspaces and the quality of those connections should foster healthier commuting patterns (e.g. walking and cycling) through efficient public transport provision, appropriate street networks and highquality streetscapes, and density and mix of uses.

Emergent working practices and changes in the organisation of work raise several challenges. Work is extending beyond the office to the home, semi-public and public spaces (Martins 2015) and steering new typologies of workspaces, calling for further integration of work and other uses in new building types, the articulation between spaces of work and open spaces, and the need to support diverse movement/ commuting patterns. Homeworking requires attention to housing design to suitably accommodate work.

The demise and delocalisation of offices and homeworking may lead to more diffuse patterns of work location (e.g. work moving to residential areas). These call for a reflection about the role of offices and the mix of activities/services needed in residential areas to support home and flexible working as well as social needs (e.g. co-working spaces).
Decreasing demand for traditional office space will have great implications for the future of business clusters and will free-up built space to be creatively re-used. The design of quality of working environments should consider the wider neighbourhood in terms of access to open and green space, social amenities, physical activities, etc.

There is an opportunity to maximise the health benefits of these trends. How can urban space support and benefit from more flexible and extended work patterns? The overlap between work, play, and sociability may contribute, for example, to enhance public spaces. The changing place of work opens an opportunity to rethink the geographies of production, living, and retail, balancing the density of activities across large urban areas, and promoting the intensity and sense of place of residential suburbs.

Finally, regarding the role of Work/Economy in Place, the major challenge concerns the loss of retail and other businesses that give life to our high streets, neighbourhoods and town centres. Changes in the location/distribution of work and the long-term trend of online retail suggest this problem is not temporary. It is thus crucial to manage more dispersed work/economic patterns to generate critical mass to support retail, and find (alternative) ways to maintain and create vibrant urban areas, for instance through new ground floor uses (potentially related to emergent ways of working) and associated building types, street interface design, and inclusive public spaces.

These reflections do not aim to provide an exhaustive agenda; these are a call for urban design to move beyond a relevant, yet narrow, focus on public space, to further embrace multidisciplinary approaches, and to engage with the multiple activities that use, appropriate and transform urban space(s). Work is a crucial arena in which to examine the consequences of the Covid-19 crisis but, more importantly, to think about and act on the post-pandemic future with the aim of building healthier, more sustainable and better urban places.

\section{References}

Avdiu, B. and G. Nayyar. 2020. When Face-to-Face Interactions Become an Occupational Hazard: Jobs in the Time of COVID19. Policy Research Working Paper 9240, The World Bank. http://documents.worldbank.org/curated/en/173701589222966 874/When-Face-to-Face-Interactions-Become-an-OccupationalHazard-Jobs-in-the-Time-of-COVID-19. Accessed 29 June 2020.

Barton, H. 2005. A Health Map for Urban Planners. Built Environment 31 (4): 339-355.

BBC News. 2020. Coronavirus: Fujitsu Announces Permanent Workfrom-Home Plan. 6 July. https://www.bbc.com/news/business53303364. Accessed 6 July 2020.

Beunderman, J., A. Fung, D. Hill, and M. Saunders. 2018. Places that Work. http://www.architecture00.net/places-that-work. Accessed 6 July 2020. 
Bird, E., J. Ige, P. Pilkington, A. Pinto, C. Petrokofsky, and J. BurgessAllen. 2018. Built and Natural Environment Planning Principles for Promoting Health: An Umbrella Review. BMC Public Health 18 (1): 930.

Duffy, F. 2008. Work and the City. London: Black Dog.

Duhl, L. and A. Sanchez. 1999. Healthy Cities and the City Planning Process: A Background Document on Links Between Health and Urban Planning. Copenhagen: WHO Regional Office for Europe. https://apps.who.int/iris/handle/10665/108252. Accessed 29 June 2020.

Ferm, J., and E. Jones. 2017. Beyond the Post-industrial City: Valuing and Planning for Industry in London. Urban Studies 54 (14): 3380-3398.

Gospodini, A. 2002. European Cities in Competition and the New' Uses' of Urban Design. Journal of Urban Design 7 (1): 59-73.

Harris, R. 2015. The Changing Nature of the Workplace and the Future of Office Space. Journal of Property Investment \& Finance 33 (5): 424-435.

Hubbard, P. 1995. Urban Design and Local Economic Development: A Case Study in Birmingham. Cities 12 (4): 243-251.

Martins, J. 2015. The Extended Workplace in a Creative Cluster: Exploring Space(s) of Digital Work in Silicon Roundabout. Journal of Urban Design 20 (1): 125-145.

Montgomery, J. 2007. Creative Industry Business Incubators and Managed Workspaces: A Review of Best Practice. Planning Practice \& Research 22 (4): 601-617.

Montgomery, J. 2005. The New Wealth of Cities: City Dynamics and the Fifth Wave. London: Routledge.

Nathan, M. 2020. The City and the Virus. Medium, 14 May. https:// medium.com/@maxnathan/the-city-and-the-virus-db8f4a68e404. Accessed 29 June 2020.

New London Architecture. 2016. WRK/LDN: Shaping London's Future Workplaces. http://legacy.newlondonarchitecture.org/ whats-on/insight-studies/insight-study-pages/wrk-ldn--2016-insig ht-study/wrk-ldn2. Accessed 6 July 2020

Nixey, C. 2020. Death of the Office. The Economist, 29 April. https:// www.1843magazine.com/features/death-of-the-office. Accessed 29 June 2020.

Perry, F. 2020. This Is What a Return to the Office Will Be like When the Lockdown Lifts. Wired UK, 5 May. https://www.wired.co.uk/ article/social-distancing-office-cubicles. Accessed 29 June 2020.
Pineo, H. 2020. Towards Healthy Urbanism: Inclusive, Equitable and Sustainable (THRIVES)-An Urban Design and Planning Framework from Theory to Praxis. Cities \& Health. https://doi. org/10.1080/23748834.2020.1769527.

Reuschke, D., and A. Felstead. 2020. Changing Workplace Geographies in the COVID-19 Crisis. Dialogues in Human Geography 10 (2): 208-212.

Sailer, K. and A. Penn. 2009. Spatiality and Transpatiality in Workplace Environments. Proceedings of the 7th International Space Syntax Symposium. Stockholm: Royal Institute of Technology (KTH).

Sarkar, C., and C. Webster. 2017. Urban Environments and Human Health: Current Trends and Future Directions. Current Opinion in Environmental Sustainability 25: 33-44.

Sarkar, C., C. Webster, and J. Gallacher. 2014. Healthy Cities: Public Health through Urban Planning. Cheltenham: Edward Elgar Publishing.

Shaw, W., C. Main, P. Findley, A. Collie, V. Kristman, and D. Gross. 2020. Opening the Workplace After COVID-19: What Lessons Can Be Learned from Return-to-Work Research? Journal of Occupational Rehabilitation. https://doi.org/10.1007/s1092 6-020-09908-9.

Stevens, Q. 2015. Creative Milieux: How Urban Design Nurtures Creative Clusters. Journal of Urban Design 20 (1): 1-7.

Urban Design Group. 2016. Industry and Urban Design. Urban Design 138. http://www.udg.org.uk/publications/urban-design-journalissue/urban-design-138-spring-2016. Accessed 6 July 2020.

Zenkteler, M., M. Foth, and G. Hearn. 2021. The Role of Residential Suburbs in the Knowledge Economy: Insights from a Design Charrette into Nomadic and Remote Work Practices. Journal of Urban Design. https://doi.org/10.1080/13574809.2020.1860673.

Publisher's Note Springer Nature remains neutral with regard to jurisdictional claims in published maps and institutional affiliations.

Juliana Martins is a Lecturer (Teaching) in Urban Design at the Bartlett School of Planning, University College London (UCL). 